University of Nebraska - Lincoln

DigitalCommons@University of Nebraska - Lincoln

Library Philosophy and Practice (e-journal)

Libraries at University of Nebraska-Lincoln

Winter 11-8-2019

Barcode Technology and its Application in Libraries

Dr. Anupam Chanda

anupamchnd1988@gmail.com

Follow this and additional works at: https://digitalcommons.unl.edu/libphilprac

Part of the Library and Information Science Commons

Chanda, Dr. Anupam, "Barcode Technology and its Application in Libraries" (2019). Library Philosophy and Practice (e-journal). 3619.

https://digitalcommons.unl.edu/libphilprac/3619 


\title{
Barcode Technology and its Application in Libraries
}

\author{
Dr. Anupam Chanda \\ Librarian, Assam Don Bosco University, Guwahati, Assam- 781017, India. \\ Contact: anupamchnd1988@gmail.com
}

\begin{abstract}
The library is one of the essential place in any academic institution. With the invention of ICT (Information and Communications Technology), every sector now a day are trying to automate their system and library is also one of them. We can find that the technologies have taken over and helped the library in various ways. Now a day's libraries need new tools that will allow them to increase their productivity and improve user service without adding personnel. Application of Barcode technology in libraries is a way to process client requests from fast to fastest. Barcode technology is mostly used in the circulation system of a library and most successful due to its speed, accuracy and reliability. Barcoding though comparatively an old technology is one of the significant steps in library automation and is still not widely used in libraries.

This article briefly discusses the description of the application of Barcode technology in libraries, its working mechanism and also the advantages and disadvantages of this technology. The researcher has tried to explore the technical aspects of Barcode technology in the library. The main aim of the article is to create awareness among the librarians to use Barcode technology in the library. Barcode is very cost-effective technology can be used by every library. The paper also discusses the creation of Barcode with Glabels open-source software which is absolutely free of cost.
\end{abstract}

Keywords: Barcode technology, Glabels, Barcode scanner.

\section{Introduction}

In recent time, libraries and knowledge centres are facing lots of changes due to the rapid growth of modern technologies. Modern technologies have replaced the out-of-date methods applied in libraries and knowledge centres for storing and disseminating of information. In the world of information technology and computerization, automation of libraries and growing demand for improved facilities to users. Library materials are also changing quickly to the various 
digital formats from the traditional print formats. In this scenario, Barcode technology plays an important role in automating the functions of the library, especially the circulation process. Application of Barcode increases the speed and accuracy in operations. Barcode technology

provides a simple and inexpensive method of encoding text information that is easily read by inexpensive electronic readers. Barcoding also allows data to be collected rapidly and with extreme accuracy.

Barcoding is a computer-aided process of generating codified information, which is subsequently printed on a predefined stationery, invariably on a self-adhesive label for several later applications. A Barcode is a combination of a series of parallel, adjacent bars and spaces. Predefined bar and space patterns or "symbologies" are used to convert small strings of character data into a printed symbol. A Barcode reader interprets a Barcode by scanning a light source across the Barcode and calculating the intensity of light replicated back by the white spaces. The pattern of replicated light is identified with a photodiode which produces an electronic signal that exactly matches the printed Barcode pattern. This signal is then construed back to the original data by inexpensive electronic circuits.

\section{Statement of the problem}

The main aim of today's libraries and resource centres in adopting Barcode technology is to improve library procedures by increasing the efficiency of library transactions, reducing workloads of the library staffs, and improving services for library users. Data obtained through Barcode is available rapidly and precisely, Barcode reduces the possibility of human errors, Barcode is inexpensive to design and print and promote better verdict making. Despite the benefits of Barcode in libraries, there are few shortcomings, having Barcode does not guarantee the effectiveness and efficiency of services rendered. There is a need to observe how the Barcodes are being executed for efficiency and effectiveness in the library. Therefore, the researchers intend to scrutinize the application of Barcode technology in the libraries.

To tied up into a fixed boundary, the discussion of this paper is limited to the key objectives, due to the lengthiness of the paper and wide speared off the technology. Though Barcode technology is now used in many sectors, this paper is limited to the library based use and services, as we are library professionals. 


\section{Objectives of the study}

* To find out the areas in which the Barcode technologies are being used in the libraries;

* To create awareness of the working mechanism of Barcode technology;

- To identify the merits and demerits of using Barcode technology in libraries.

\section{Methodology}

The entire study is based on the use and effectiveness of Barcode technology in the library. The paper starts with an introduction, objectives, and some literature reviewing of the similar types of study. Later it elaborates about the technology, a short history, designing methods with some prescribed formats, system requirements for initiatives, its advantages and disadvantages and the initiative and implications of this technology in the library.

\section{Literature Review}

Akanbi et al. (2018) conducted a survey on the application of Barcode technology in Landmark University Centre, on their survey they found that The main objective of any library for the adoption of Barcode technology is to improve library processes reducing workplace injuries, and enlightening services for library users. This study, therefore, examines the application of Barcode technology in landmark university centre for learning resources, Omu-Aran Experience. The researchers have collected data through questionnaire and data was analyzed using IBM-SPSS version 20.0. Descriptive statistics were used to present the data for better explaining and detailed descriptions were given where essential. The finding of the study reveals that one of the factors affecting the use of Barcode technology in Center for Learning Resources are a constant lookup of database which is always necessary due to the fact that Barcode doesn't save data of the book nor the system status.

Fatima and Ansari (2017) on their study mentioned that the department of library and information science of Aligarh Muslim University is the first department which introduced Barcode technology in its library. The authors have tried to assess the impact of Barcode technology in seminar library and also point out that the users of the seminar library have been benefitted with the application of Barcode technology. The interview method was applied to seek opinions from students, research scholars and faculty members of the department regarding the utility of Barcode in seminar library.

Rahaman (2016) on his article mentioned that Barcode, QR code and RFID are becoming very useful technology not only to serve the users' but for library security also. The overall 
technology, its uses, benefits, challenges of using these technologies were also conferred here. At the end, a case study has been done on Central Library, NIT, Rourkela about implement and uses of these technologies and proficient their users' satisfaction.

Islam and Shuva (2010) on their study explored the usage and applications of Barcode technologies. A survey has been carried out in eight libraries in Dhaka City of Bangladesh. The survey included the following: Inception year, software used to Barcode, areas in which Barcodes are being used in libraries, training of library staff, and gratification of users and information specialists and also the merits and demerits of Barcode technologies in the library.

\section{About Barcode Technology}

A Barcode is a square or rectangular image containing a series of analogous black lines and white spaces of varying widths. Barcode is a machine-readable code in the form of numbers and an outline of parallel lines of varying widths, printed on a commodity. Hence a Barcode fundamentally is a way to encode information in a pictographic pattern that a machine can read. The combination of black and white bars signifies different text characters which follow a set algorithm for that particular Barcode.

\section{Invention of Barcode}

* 1948: Bernard Silver (1924-1963) and N. Joseph Woodland (1921-) get the idea for emerging grocery checkouts that can mechanically scan products. Woodland tries various different marking arrangements, including lines and circles, marks stimulated by movie soundtracks, and dots and dashes based on Morse code. In October 1949, the two originators refine their system to use bullseye patterns and apply for a patent (US Patent $\# 2,612,944)$, which is granted on October 7, 1952. Their early Barcode-scanning equipment uses an orthodox lamp to lighten product labels and a photomultiplier (a crude type of photoelectric cell) to read the light reflected off them. In 1951, Joe Woodland joins IBM to work on Barcode technology, though the company declines to purchase his patent, which is attained by Philco (and later RCA).

* 1960s: RCA develops a number of profitable applications until the patent expires in 1969. Work on bullseye Barcodes continues, but they prove undependable and gradually fall by the wayside. 
* 1970: By now, grocery stores are beginning to explore the idea of using their own product coding and marking systems, but different stores are allowing for different systems, and this threatens to cause difficulties for large food producers who sell branded goods to multiple retailers. Under the guidance of Alan Haberman (1929-2011), executive vice president of First National Stores in Boston, the stores come structured to form the Uniform Code Council (UCC), later known as GS1 US, the organization that now manages Barcode standards worldwide.

* 1971: Meanwhile, at IBM, engineer George J. Laurer (1925-) builds on Woodland's ideas to develop the Universal Product Code (UPC) - the modern black-and-white striped Barcode. (Read more about Laurer's work and IBM's contributions to Barcode technology.)

* 1973: After examining a variety of different marking systems, Haberman's grocery stores committee settles on IBM's rectangular UPC as the standard grocery Barcode. Although he didn't invent the Barcode, Haberman is widely credited with its universal adoption.

* 1974: On June 26, the world's first grocery-store Barcode scanner goes into use at Marsh's Supermarket, Troy, Ohio in the United States. The first scanned purchase, made by Clyde Dawson, is for a 10-pack of Wrigley's chewing gum.

* 1979: In the UK, a Barcode scanner is used for the first time at Key Markets in Spalding, Lincolnshire.

* 2011: Joe Woodland and the late Bernard Silver are initiated into the National Inventors Hall of Fame in recognition of their brilliant invention. (Woodford, 2018).

There are two types of Barcode one is 1D (1-Dimensional) and other is 2D (2-Dimensional).

* “1D” Barcode is used in normal products like groceries, pen, and electronic equipment's etc.

* “2D” is similar to 1-Dimensional Barcode, but it can store more data per unit area as compared to the 1D. You must have seen the use of 2D Barcode in the Paytm App. 
1D barcodes:
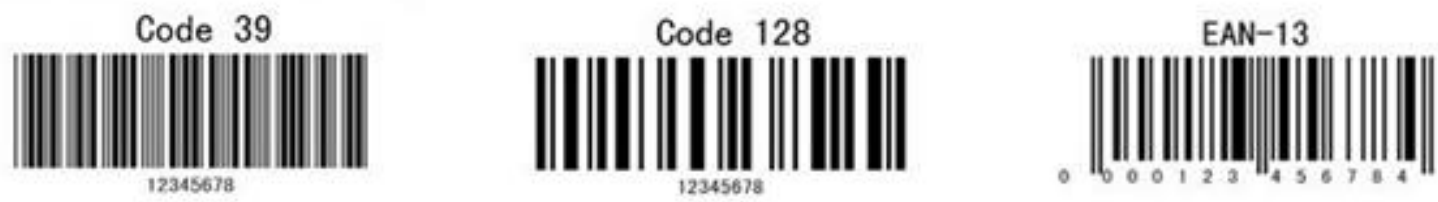

2D barcodes:
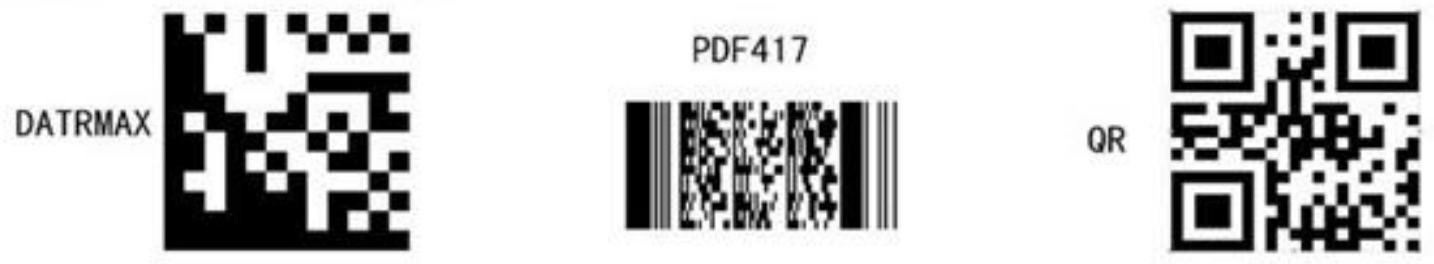

Fig 1: Types of Barcode

How Barcode is made?

A Barcode has 95 blocks.

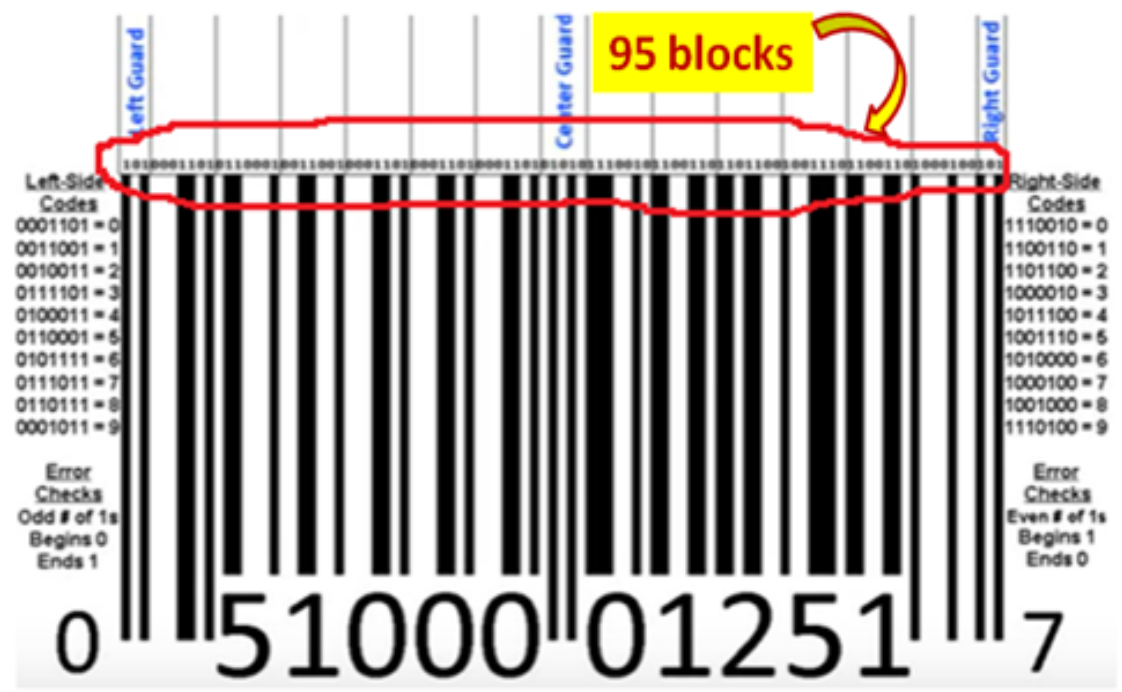

Fig 2: 95 Blocks of Barcode 
The Barcode is transcribed in the 12 blocks out of 95 blocks.

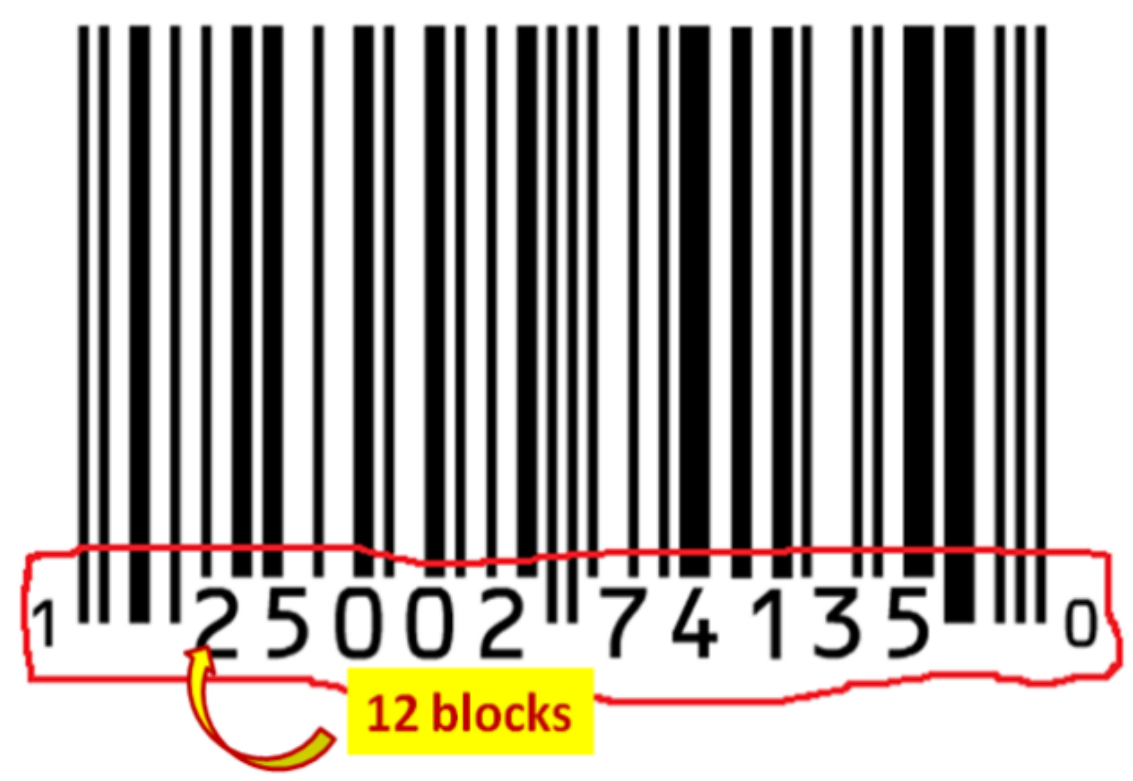

Fig 3: 12 Blocks of Barcode

Out of these 95 blocks three blocks are named as the: Left guard; Centre guard; and Right guard.

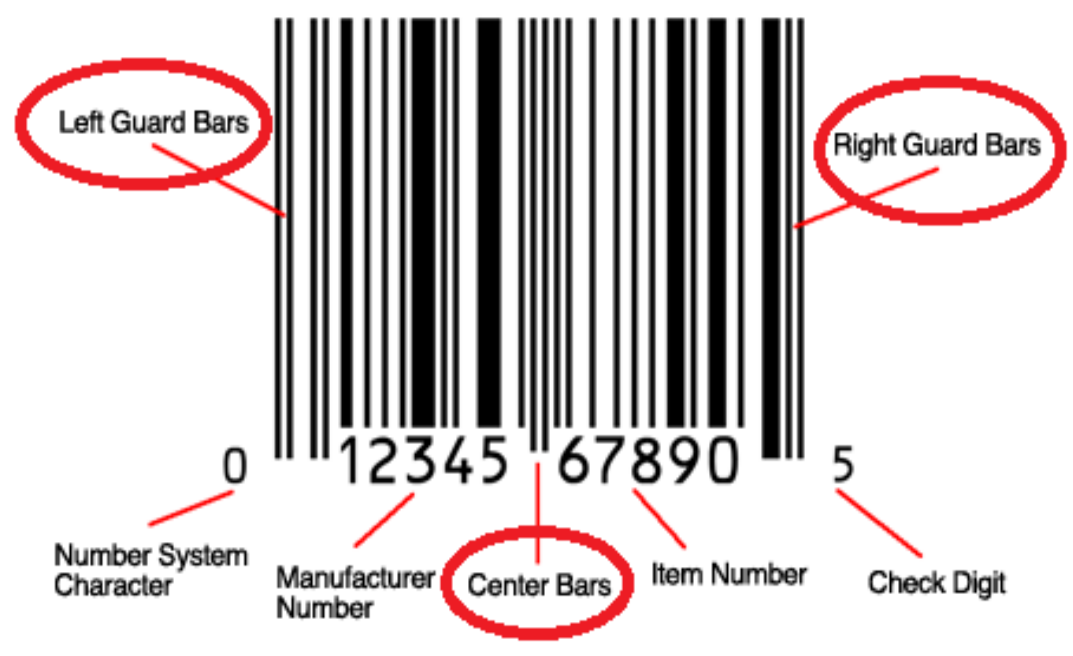

Fig 4: Guards of Barcode

How does Barcode work?

As we know that a Barcode is a square or rectangular image containing a series of parallel black lines and white spaces. The information is programmed among the length of each shaded line and the space between them. 
* A scanning device uses a laser to "read" the Barcode by scanning in the unique bar of shaded lines.

* A Barcode scanner reads the lines from left to right.

* A Barcode scanner reads the pattern of black and white bars which turns the information in the binary code ( 0 or 1$)$. The computer reads the information in the binary forms only and the same is displayed on the screen of the monitor.

\section{Barcode assigned to different countries of the world}

1. India: 890

2. United States and Canada: $00-13$

3. France: 30-37

4. Germany: 40-44

5. Japan: 45-49

6. Russia: 46

7. Taiwan: 471

8. Sri Lanka: 479

9. Philippines: 480

10. Hong Kong: 89

11. United Kingdom: 50

12. China: 690-692. (Singh, 2018).

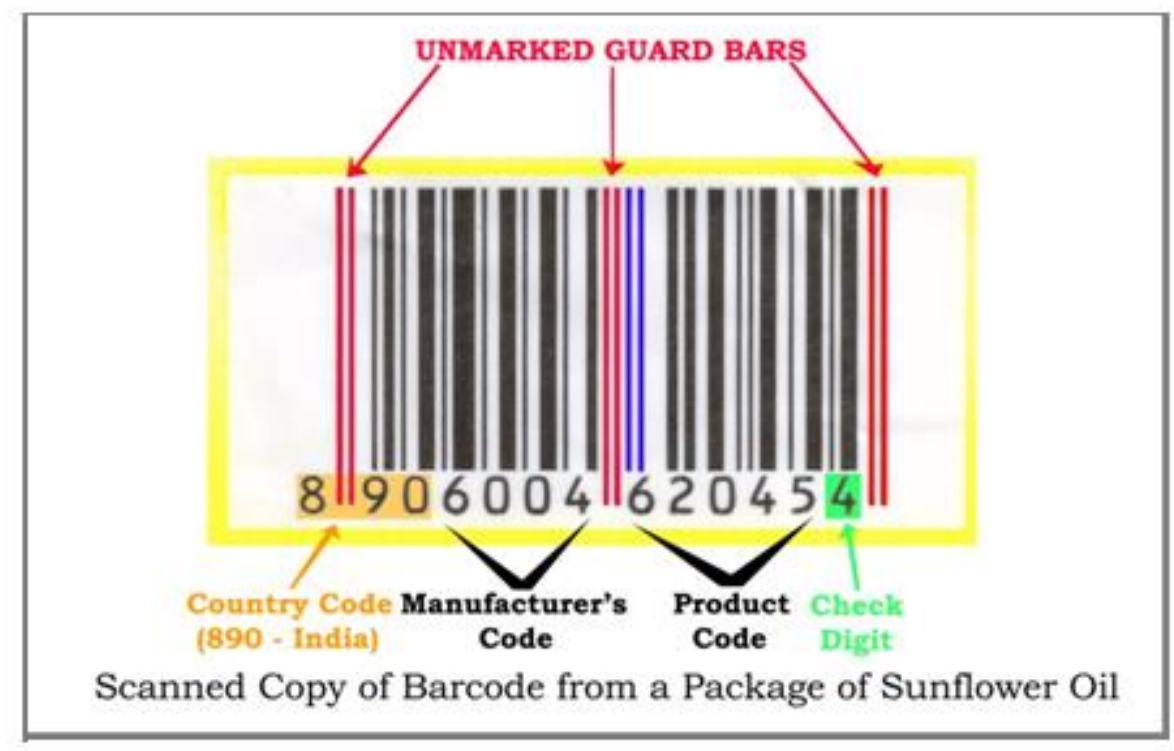

Fig 5: Details of the guards of Barcode 


\section{How does a Barcode scanner work?}

It would be not good having Barcodes if we didn't have the equipment to read them. Barcode scanners have to be capable to read the black-and-white zebra lines on products tremendously, quickly and nourish that information to a computer or checkout terminal, which can identify them instantly using a product database. Here's how they do it.

Let's assume that Barcodes are simple on-off, binary patterns with each black line equivalent to a one and each white line a zero.

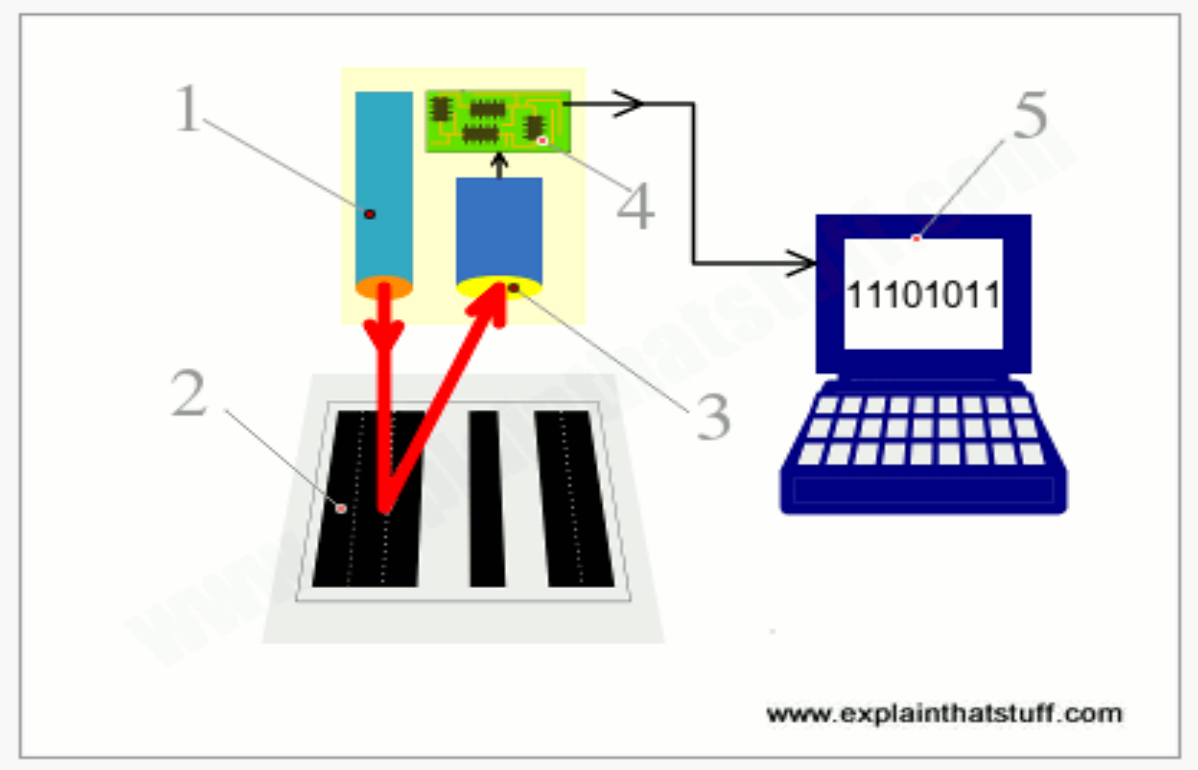

Fig 6: Working process of Barcode scanner

1. Scanning head shines LED or laser light onto Barcode.

2. Light replicates back off Barcode into a light-detecting electronic element called a photoelectric cell. White areas of the Barcode replicate most light; black areas reflect least.

3. As the scanner moves past the Barcode, the cell produces a pattern of on-off pulses that agree to the black and white stripes. So for the code shown here ("black black black white black white black black"), the cell would be "off off off on off on off off."

4. An electronic circuit attached to the scanner transforms these on-off pulses into binary digits (zeros and ones).

5. The binary digits are sent to a computer attached to the scanner, which identifies the code as 11101011. (Woodford, 2018). 
In some scanners, there is a single photoelectric cell and, as we move the scanner head past the product, the cell detects each part of the black-white Barcode in turn. In more sophisticated scanners, there is a whole line of photoelectric cells and the entire code is perceived in one go.

In reality, scanners do not detect zeros and ones and produce binary numbers as their output: they detect orders of black and white stripes, as we have shown here, but convert them directly into decimal numbers, giving a decimal number as their output.

\section{Barcode and its Application in the Libraries}

Barcode system is mainly suitable for supporting the circulation functions of a library. With the help of Barcode technology, library inventory and periodical control can also be carried out effectively and efficiently, users can submit his/her identity cards and the library staffs can scan the Barcode available in the identity card with a Barcode scanner and access the borrowing status. If the Barcode system allows the borrowing facilities, the library staffs can scan the documents accession number (Barcode) and can be issued to the user comfortably within a few seconds, most importantly there is less chance of error which is more important for any library.

\section{Basic requirements for Barcode applications in the library}

Implementing Barcodes in library applications following hardware and software are required:

* Personal computers, (PCs);

* Barcode Printing software;

* Barcode printer

* Barcode Scanner;

* Decoder;

* Library management software; and

* Membership database;

* Bibliographic database of library users.

\section{Usage of Barcode technology in the library}

- Accessioning

When a library obtains a new book it has to be given a serial number which is called accession number. Information about the book such as title, author, subject, keywords etc. has been recorded after assigning an accession number. After assigning accession number, 
Barcode usually matching with the accession number is created. Afterwards, Barcode labels are printed and pasted at the specified place on the books. Entered bibliographic data helps in identification of book through Barcode. In almost all library automation software, two options are available viz. system-generated Barcode or user-defined.

\section{- Membership identification}

With the help of Barcode technology, library staff can identify the membership status of a user. For that Barcode is to be printed on the library membership card, the Barcode will be scanned by the Barcode scanner and the data will be transformed through library management software. In the library management software, details of the user will be displayed.

\section{- Circulation}

Barcode is mostly useful for circulation, the main motive of using the Barcode in the library is for circulation of library materials. The accession number of the book or study material are to be converted into Barcode and has to be pasted inside the book or study material. Library staff in the circulation section than can easily scan the Barcode and can issue/return the book to the users in a quick time, most importantly the transaction is error-free.

\section{- Library attendance system}

Barcode can also be used to monitor the entry and exit time in the library. One Barcode scanner has to be set up in the entrance of the library. Every time when the user comes to the library, they need to scan the Barcode available in their library membership card, which will automatically take the attendance, which can later be downloaded in the excel file.

\section{- Issue of "no due" certificate}

No dues certificate is issued when any member leaves the organization and his/her membership is cancelled then the library issues no dues certificate. This process is timeconsuming and error-prone in a manual system. In a computerized system using Barcode technology, the member surrenders his/her identity card and the counter staff can scan it. The automation package will search the database for any document issued in his/her name. If nothing is due, no dues certificate will be printed.

\section{- Inventory and periodical control}

For the periodicals control system, the primary task is to develop a database of periodicals holdings and assign code numbers for each periodical. Each periodicals record may contain 
information such as title, volume number, year of publication, frequency, publisher, price etc. The database may be updated periodically. For each periodical, Barcode is created, based on the code number and pasted on the lower card maintained for each periodical in the Kardex system. When a particular issue is received, its respective Barcode is scanned for months and issue numbers.

\section{- Stock verification}

The manual system of stock verification is very unwieldy but with the help of Barcode, the library professional can easily check the stock of the library. Library professional carrying the handheld scanner attached with Barcode reader checks the available books on the stack and this data can be transferred on the server and can be downloaded. By further dispensation, library staff may know about books issued, books sent to the bindery etc. Subsequently, the software will generate a list of missing books. In this way, the valuable time of library staff can be saved in the lengthy and tedious work related to stock verification

\section{Advantages of Barcode technology in the library}

* Barcodes eliminate the possibility of human error in the circulation section of the library

* Barcodes are inexpensive to design and print. Generally, they cost mere pennies, regardless of their purpose, or where they will be affixed.

* Barcodes are extremely versatile. They can be used for any kind of necessary data collection in the library.

* Library material control improves. Because Barcodes make it possible to track library materials so precisely.

* Data obtained through Barcodes are available rapidly. Since the information is scanned directly into the server, it is ready almost instantaneously.

* Barcodes promote better decision making. Because data is obtained rapidly and accurately, it is possible to make more informed decisions. Better decision making ultimately saves both time and money.

\section{Disadvantages of Barcode technology in the library}

They are very labour intensive; as they must be scanned individually.

- Barcodes are more easily damaged; as the line of sight is needed to scan, the printed Barcode has to be exposed on the outside of the library materials. 
If a Barcode is ripped or damaged there is no way to scan the library materials.

* Restricted traceability.

* Susceptible to environmental damage.

* Prone to Human Error

\section{Generate Barcode with Glabels open-source software in Ubuntu}

In order to generate Barcode, you have to first install Glabel software (Run only on Linux). This software is free in nature and can be used for this purpose and Barcode can be generated with CSV file easily on different size of labels.

\section{To use the Glabels, following are the steps:}

Step - 1: Install the glabels software in Ubuntu (Execute the following command in the terminal)

sudo apt-get install glables

Once it is installed, you can find it in Ubuntu application.

Step - 2: Prepare the list of accession / Barcode numbers in excel file and save in .csv format. (Give column heading as Barcode and add the Barcode/accession number in the same column as much as you wish to add.)

Step - 3: Now, download a Glabel template.

Step - 4: Now open the Glabel template with Glabel software (You can double click or right click and choose to open with Glabel software) change the name of the library.

Step - 5: Click on Objects - Merge Properties (It will open another window).

* Now click on the location box and add the CSV file which you have generated through the report module or prepared in excel sheet.

* It will show the accession number. Now click on OK button.

Step - 6: Print the Barcode.

* Now click on File - Print (You can directly print with your printer on the label or can generate PDF file and printer later).

\section{Conclusion}

Application of information technology in libraries had greatly changed the way of performing different functions and has brought efficiency, accuracy and accountability. Barcode technology has helped particularly in circulation and stock take process. Barcode technology is 
cheaper and integrated with prominent library automation software packages. Therefore, a majority of automated libraries in India have been using this technology.

Technology always advances with time. Barcode helps to overcome the problems faced in inputting data through keyboards in computerized circulation systems and achieve maximum efficiency. Barcode can automate the process of data entry and in reach of the library profession. Many libraries still are not using any automatic identification technology like Barcode or RFID in their libraries. Because of the lack of awareness, the librarians' do not know how to use these technologies in the library, so in this article, the researcher tries to discuss the usefulness and the process how to use Barcode technology in the library. Barcode can freely be generated by using Glabels open source software.

\section{Journals}

\section{Reference}

Akanbi, L. M., Bashorun, M. T., Salihu, U. A., Babafemi, G. O., Sulaiman, K., \& Kolajo, S. O. (2018). Application of Barcode Technology in Landmark University Centre for Learning Resources, Omu- Aran Experience. Library Philosophy and Practice (e-Journal). Retrieved from http://digitalcommons.unl.edu/libphilprac/2088

Fatima, S., \& Ansari, M. A. (2017). Barcode Technology and its Impact on Seminar Library, Department of Library and Information Science, Aligarh Muslim University. Journal of Advancements in Library Sciences, 4(3), 81-85. Retrieved from http://sciencejournals.stmjournals.in/index.php/JoALS/article/download/19/20

Islam, M. S., \& Shuva, N. Z. (2010). Barcode technology and its use and applications: A study of selected libraries of Bangladesh. International Information \& Library Review, 42(1), $27-$ 33. doi: 10.1080/10572317.2010.10762839

Kolhe, P. R., Dharaskar, R. M., Tharkar, M. H., Joshi, S., Desai, S., \& Dapoli, B. S. K. K. V. (2016). Information Technology Tool in Library Barcode \& Radio Frequency Identification (RFID). IJISET - International Journal of Innovative Science, Engineering \& Technology, 3(1), 81-86. Retrieved from http://ijiset.com/vol3/v3s1/IJISET_V3_I1_11.pdf

Patel, D. R. (1996). Barcode system in libraries - it's uses and importance. Annals of Library Science and Documentation, 43(1), 1-10. Retrieved from http://nopr.niscair.res.in/bitstream/123456789/27529/1/ALIS 43(1) 1-10.pdf 
Rahaman, W. (2016). ENHANCING LIBRARY SERVICES USING BARCODE, QR CODE AND RFID TECHNOLOGY: A CASE STUDY IN CENTRAL LIBRARY NATIONAL INSTITUTE OF TECHNOLOGY, ROURKELA. International Journal of Digital Library Services, 16(3), 39-50. Retrieved from http://www.ijodls.in/uploads/3/6/0/3/3603729/3950.pdf

Singh, G., \& Sharma, M. (n.d.). Barcode technology and its application in libraries and information centers. International Journal of Next Generation Library and Technologies, 1(1), 1-8. Retrieved from http://www.ijnglt.com/files/Barcode technology and its application in libraries and Information centers.pdf

\section{Website}

Singh, H. (2018, April 2). What is Barcode and how is it made? Retrieved November 4, 2019, from https://www.jagranjosh.com/general-knowledge/what-is-Barcode-and-how-is-it-made1522059273-1.

Williams, K. (2018, October 11). Everything You Need To Know About How Barcode Scanners Work. Retrieved November 4, 2019, from https://www.shopkeep.com/blog/how-doBarcode-scanners-work\#step-1.

Woodford, C. (2018, December 26). How do barcodes and barcode scanners work? Retrieved November 4, 2019, from https://www.explainthatstuff.com/barcodescanners.html. 